\title{
INOVASI PEMBELAJARAN AKUNTANSI DI YOUTUBE MENYONGSONG INDONESIA EMAS 2045
}

\author{
Agus Suharsono \\ Balai Diklat Keuangan Yogyakarta, Badan Pendidikan dan Pelatihan Keuangan \\ gusharpramudito@gmail.com
}

Diterima 27 Februari 2021

Disetujui 28 Mei 2021

\begin{abstract}
Indonesia is currently launching an era of demographic bonuses in which the productive population is more dominant than the non-productive population. They are the golden generation that will realize Indonesia Golden 2045. The subject of this research is about innovation in accounting learning to realize the educational goals of 2020, namely capacity building, modernization of the learning process with the use of technology, strengthening services, easy access, and can be felt by all levels of society. The method used is qualitative, data in the form of accounting learning videos on YouTube which are analyzed logically-inductively and then presented descriptively. The results of the study note that there is already an accounting learning video on YouTube but its nature is scattered so that it cannot be used as a complete learning medium for this purpose it is necessary to collaborate with several parties to create an integrated Accounting Learning account and complete one course in accordance with the established curriculum. In order for the video display to suit the tastes of the learner, the making involves students across campus. A complete accounting learning video can be used as a learning media with a blended learning system so that faceto-face meeting is more effective for practice and case studies.
\end{abstract}

Keywords: Accounting Learning; Millennial Generation; YouTube; Indonesia Gold 2045.

\section{PENDAHULUAN}

\subsection{Latar Belakang}

Indonesia merupakan salah satu anggota Perserikatan Bangsa-Bangsa yang berperan aktif dalam penentuan sasaran Tujuan Pembangunan Berkelanjutan. Transforming Our World: The 2030 Agenda for Sustainable Development bidang Pendidikan merupakan Goal 4: Ensure inclusive and equitable quality education and promote lifelong learning opportunities for all (UN, 2015). Peraturan Presiden Nomor 59 Tahun 2017 tentang Pelaksanaan Pencapaian Tujuan Pembangunan Berkelanjutan bertujuan agar Sustainable Development Goals selaras dengan Rencana Pembangunan Jangka Panjang Nasional dan Rencana Pembangunan Jangka Menengah Nasional dengan target yang akan dicapai adalah pendidikan tinggi tanpa dipungut biaya, setara, terjangkau, dan berkualitas, yang mengarah pada capaian pembelajaran yang relevan dan efektif. Tahun 2045 pusat perekonomian dunia diperkirakan bergerak ke Asia, seperti China, India, Korea Selatan, dan Jepang karena beberapa faktor penentu yaitu demografi, urbanisasi global, perdagangan internasional, keuangan global, kelas pendapatan menengah, persaingan sumber daya alam, perubahan iklim, kemajuan teknologi, perubahan geopolitik, dan perubahan geoekonomi. Untuk mencapai tujuan pendidikan dalam era Generasi Emas 2045, Kemendikbud menetapkan sebuah peta jalan dengan tiga tahap sasaran pendidikan. Sasaran Pendidikan tahun 2020 masuk tahap pertama dengan fokus pada peningkatan kapasitas, modernisasi proses pembelajaran dengan pemanfaatan tehnologi, penguatan layanan, kemudahan akses, dan dapat dirasakan seluruh lapisan masyarakat (Kemendikbud, 2017). 
Indonesia saat ini memasuki era bonus demografi ditandai dengan menurunnya rasio ketergantungan yaitu perbandingan penduduk nonproduktif dan penduduk produktif, semakin kecil rasionya semakin besar penduduk produktif. Rasio ketergantungan Indonesia berdasarkan proyeksi data Sensus Penduduk 2010, tahun 2012: 49,6 dan mencapai titik terendah tahun 2028-2031: 46,9. Namun, berdasarkan hasil proyeksi Supas 2015, rasio ketergantungan terendah diperkirakan mengalami percepatan tahun 2021-2022: 45,4 dan berakhir tahun 2036-2037. Bonus demografi Indonesia adalah kaum milenial. Hasil studi yang dilakukan oleh Boston Consulting Group bersama University of Berkley tahun 2011, karakteristik generasi milenial USA adalah: 1) minat membaca konvensional menurun, lebih memilih membaca lewat smartphone, 2) wajib memiliki akun sosial media sebagai alat komunikasi dan pusat informasi, 3) pasti lebih memilih ponsel daripada televisi, dan 4) menjadikan keluarga sebagai pusat pertimbangan dan pengambil keputusan mereka. Menurut Susenas 2017 jumlah generasi milenial 88 juta jiwa atau 33,75\% dari total penduduk Indonesia. Pemanfaatan telepon seluler generasi milenial tahun 2015: 82,64\%, Tahun 2016: $83,51 \%$, tahun 2017: 91,62\%. persen pada tahun 2017. Sedangkan penggunaan internet tahun 2015: 40,78\%, tahun 2016: 46,29\%, dan tahun 2017: 56,42\% (BPS, 2018). Penduduk Indonesia yang aktif bermain media sosial mencapai 150 juta orang, YouTube: 88\%, Whatsapp: 81\%, Facebook: 81, dan Instagram: 80\% dengan lama berselancar sekitar tiga jam per hari (Yudhistira, 2019). YouTube jadi aplikasi media paling populer di Indonesia, terdapat 50 juta pengguna aktif YouTube per bulan (Ayuwuragil, 2018). Berdasarkan data tersebut pokok bahasan penelitian ini adalah bagaimanakah inovasi pembelajaran akuntansi di YouTube bagi generasi emas milenial menyongsong Indonesia Emas 2045, dengan tujuan memberikan altenatif solusi pembelajaran sesuai dengan sasaran pendidikan tahun 2020 yang fokus pada peningkatan kapasitas, modernisasi proses pembelajaran dengan pemanfaatan tehnologi, penguatan layanan, kemudahan akses, dan dapat dirasakan seluruh lapisan masyarakat.

\subsection{Telaah Literatur}

Istilah generasi emas, dimunculkan Menteri Pendidikan dan Kebudayaan pada sambutan Peringatan Hari Pendidikan Nasional pada tanggal 2 Mei 2012 memunculkan istilah generasi emas karena Indonesia dikaruniai bonus demografi jumlah usia produktif yang besar (Rahmat, 2016). Bonus demografi baru pertama kali terjadi sejak Indonesia merdeka harus dikelola dengan baik melalui Pendidikan agar tidak berubah menjadi bencana demografi (Triyono, 2016). Pendidikan merupakan usaha sadar dan terencana untuk mewujudkan suasana belajar dan proses pembelajaran agar peserta didik secara aktif mengembangkan potensi diri sehingga siap menghadapi kehidupan sesuai zamannya yang dapat dikategorikan menjadi tiga kecakapan yaitu literasi dasar, kompetensi, dan kualitas karakter (Iriawan, 2017). Pendidikan merupakan kunci untuk menghadirkan sumberdaya manusia yang andal, mengubah sikap, dan menambah ilmu. Pendidik menghadapi tantangan mewujudkan pendidikan berkualitas, kreatif, inovatif, dan inspiratif (Darman, 2017). Untuk menyiapkan generasi emas agar dapat mewujudkan Indonesia Emas 2045 perlu peran semua elemen masyarakat menciptakan pendidikan karakter dan relijius (Wardoyo, 2015).

Generasi emas adalah penyangga keutuhan, integritas, dan martabat bangsa sehingga pendidikan juga harus mampu menanamkan Pancasila sebagai karakter jati diri bangsa (Dongoran, 2014). Muatan materi pendidikan karakter yang holistik dan komprehensif berbasis Pancasila, tidak hanya mentransfer ilmu tetapi juga nilai-nilai berbasis tiga aspek yakni nilai kejujuran, nilai kebenaran dan nilai keadilan (Abi, 2017). Beberapa penelitian terdahulu perlu inovasi pembelajaran bagi generasi emas agar mampu mewujudkan Indonesia Emas 2045. Metode pembelajaran yang tepat berpengaruh terhadap motivasi belajar siswa 
sehingga tidak boleh memilih model pembelajaran yang menyebabkan peserta tidak senang, bosan, dan tidak bersemangat (Mujiman, 2007). Metode kelas inspirasi bisa menggunakan media yang dapat membuat siswa menjadi aktif dan kreatif, memberi tugas untuk dikerjakan di rumah, dan memotivasi untuk menemukan ide-ide baru untuk mengembangkan pengetahuan dan keterampilannya (Utami, 2017). Selain itu perlu dikembangkan model pembelajaran student centris, problem based learning, contextual teaching learning, cooperatitive learning, dengan scientific approaches. Yang lebih penting model pembelajaran yang menghasilkan lulusan yang kreatif, inovatif, progresif, percaya diri, berani mengambil resiko, menjiwai nilai-nilai agama, nasionalisme, dan Pancasila (Nata, 2015). Agar pembelajaran berpusat pada pembelajar perlu penggunaan media pembelajaran yang dapat meningkatkan interaksi antar pengajar dan pembelajar dan membantu pembelajar memahami materi pembelajaran (Mashoedah, 2015). Namun tidak ada metode pembelajaran satu lebih baik dari yang lain, tergantung pada tujuan yang ingin dicapai, karakteristik siswa, dan nilainilai masyarakat (Arends, 2013).

Model pembelajaran yang cocok untuk generasi emas Indonesia adalah pembelajaran gotong royong inovatif yang dikembangkan dari teori belajar konstruktivisme dari Piaget dan Vygotsky yang mendasarkan pada premis bahwa pengetahuan terbina dari interaksi kumpulan dalam menyelesaikan masalah. Model pembelajaran ini menanamkan unsur saling ketergantungan positif yang mengharuskan untuk gotong royong yang diperlukan dalam kehidupan nyata (Slam, 2015). Tercapainya Indonesia Emas 2045 dipengaruhi kesiapan Generasi Emas Indonesia dalam menghadapi Era Revolusi Industri 4.0 dalam pemanfaatan teknologi digital yang saat ini masih rendah karena ketidakmampuan membedakan berita palsu dan berita benar, serta hanya menjadi konsumen, belum menjadi produsen (Hasudungan \& Kurniawan, 2018).

Transformasi digital akan terus mengubah segala sesuatu secara mendasar mulai dari cara kita berpikir, bersosialisasi, berkomunikasi, menganalisa, berpemerintahan, bahkan dalam melakukan perencanaan akan berubah secara fundamental. Selain itu transformasi digital memudahkan pemerintah dan swasta dalam memenuhi kebutuhan setiap orang yang akan berdampak pada inovai, akselerasi, efidensial, produktifitas, inklusivitas, kolaborasi, dan akuntabilitas di semua sektor pembangunan (BAPPENAS, 2019). Juga akan membawa perubahan besar di bidang Pendidikan, transformasi digital membantu inovasi proses belajar dan meningkatkan kinerja dengan membuat, menggunakan, dan mengelola proses yang efektif dan efisien (Wanda, 2017). Diperlukan cara berpikir yang kreatif dan inovatif untuk dapat turut serta dalam kemajuan ini (Ferreira \& Serpa, 2018). Salah satunya dengan inovasi pembelajaran akuntasi di YouTube menyongsong Indonesia Emas 2045.

YouTube menjadi pilihan karena memberi altenatif media pembelajaran yang menyediakan banyak pengetahuan, mulai dari informasi berita nasional maupun internasional, hiburan, ilmu pengetahuan penunjang kuliah, dan kreativitas bermusik ataupun karya lainnya (Sianipar, 2013). Selain itu menonton video online dapat menjadi pengalaman yang menyenangkan dibanding membaca artikel atau melihat gambar karena memberikan gambaran yang lebih jelas mengenai sebuah informasi dan memenuhi eleman mystery, sensuality, dan intimacy (Handayani, 2013). Pembelajaran menggunakan video di YouTube mempermudah akses peserta didik dalam belajar karena online. Eksperimen perbandingan pembelajaran kelas yang menggunakan video Yotube dan menggunakan bukuk teks dalam pelajaran Bahasa Inggris menunjukkan bahwa video YouTube lebih efektif daripada buku teks (Kurniawati, 2013). YouTube dapat digunakan sebagai pengembangan pembelajaran yang user friendly, pembelajar mudah mengakses untuk memahami materi, pengajar mudah menyampaikan bahan ajar, karena dilakukan secara online (Pradikta \& Haryono, 2015). 
Video di YouTube menawarkan sumber data yang lebih kaya dan telah terbukti bermanfaat, juga dalam pembelajaran. Pembelajar tidak diajar pengetahuan deklaratif atau mengungat konsep, tetapi bagaimana cara mendapatkan pengetahuan agar mereka memiliki ketrampilan belajar dengan model pembelajaran kolaboratif secara konsisten agar pembelajar mampu memecahkan masalah yang dihadapi (Savira, 2011). Selain itu informasi dapat dibuat dan dipublikasikan secara bebas, unik, dan kreatif YouTube, tren baru komunikasi siber mudah menjadi viral, melalui tahapan: like, share, comment, dan subscribe (Permana \& Yusmawati, 2019). Penelitian eksplorasi materi ajar di YouTube sebagai aplikasi konten berbasis video terbesar di dunia menunjukkan bahwa dengan YouTube dapat memperkaya materi pelajaran dan dapat menciptakan lingkungan belajar yang konduktif sehingga meningkatkan pemahaman pembelajar. YouTube membantu dosen dan mahasiswa dalam mengeksplorasi materi perkuliahan, jika digabungkan dengan Facebook mampu mengubah gaya belajar kelas yang kaku menjadi lingkungan belajar yang lebih luas dan global (Abdilla, 2017). YouTube merupakan jaringan media sosial populer yang memungkinkan interaksi gratis di antara pengguna tentang video tertentu. Hasil penelitian menunjukkan bahwa konten lebih penting daripada pembuatan videonya. Video dengan durasi pendek namun komprehensif lebih diminati (Lau, 2017).

Pemanfaatan YouTube untuk media pembelajaran ekonomi-akuntansi belum digunakan secara maksimal, video yang sudah adapun belum dapat merepresentasikan konten dengan menarik, lebih banyak video pembelajaran dibidang seni dan hobi. Mahasiswa Program Studi Pendidikan Ekonomi FKIP UKSW sebagai responden berpendapat bahwa video pembelajaran berbasis YouTube layak digunakan sebagai media pembelajaran ekonomi-akuntansi dan perlu dikembangkan dimasa depan (Luhsasi, 2017). Proses pembuatan video pembelajaran di YouTube dapat menerapkan prosedur pengembangan Borg \& Gall, yaitu: 1) analisis produk yang akan dikembangkan, 2) pengembangan produk awal, 3) validasi ahli dan revisi produk, 4) uji coba terbatas dan revisi produk, dan 5) uji coba utama dan revisi produk akhir. Secara lebih sederhana dapat menggunakan prinsip Tri-N dari Ki Hadjar Dewantara, yaitu: 1) niteni dengan mengamati kelebihan dan kelurangan video yang sudah ada, 2) nirokake membuat video yang sama, dan 3) nambahi atau menginovasi dengan menutup kelemahannya (Tri, Andry, Ikasari, \& Dinta, 2018).

\section{METODOLOGI DAN ANALISIS DATA}

Penelitian ini mengunakan metode kualitatif, sumber data utama adalah kata-kata, tindakan, dan dokumen (Moleong, 2015). Data penelitian ini adalah video pembelajaran akuntansi di YouTube dengan sampling purposive yang dipilih dengan pertimbangan tertentu (Sugiyono, 2015). Data yang terkumpul dianalisis secara logiko-induktif untuk memahami pola dan kecenderungan dalam data melalui tiga tahap yaitu pengkodean, mendeskripsikan karakteristik utama, dan menginterpretasikan data (Mertler, 2011). Hasil penelitian ini disajikan secara deskriptif

\section{HASIL PENELITIAN DAN DISKUSI}

Penelitian dilakukan dengan mencari video pembelajaran akuntasi yang ada di YouTube dengan cara memasukkan kata kunci "akuntansi" dan "accounting" kemudian dipilih secara purposive empat akun YouTube dengan jumlah subscribers, video, viewers, like, dislike, durasi, dan comments terbanyak sebagaimana Tabel 1. 
Tabel 1 Akun YouTube Materi Akuntansi Dengan Subscribers, Video, Viewers, Like, Dislike, Durasi, dan Comments

\begin{tabular}{|c|c|c|c|c|c|}
\hline \multicolumn{2}{|c|}{ Uraian } & $\begin{array}{l}\text { Akuntansi } \\
\text { Pendidik }\end{array}$ & $\begin{array}{l}\text { Accounting } \\
\text { Stuff }\end{array}$ & $\begin{array}{c}\text { Ruang } \\
\text { Akuntansi }\end{array}$ & $\begin{array}{l}\text { Universitas } \\
\text { Terbuka TV }\end{array}$ \\
\hline \multicolumn{2}{|l|}{ Joined } & $05 / 11 / 2017$ & $04 / 05 / 2018$ & $01 / 09 / 2016$ & $05 / 03 / 2015$ \\
\hline \multicolumn{2}{|c|}{ subscribers } & $32.5 \mathrm{~K}$ & $47.6 \mathrm{~K}$ & $10.8 \mathrm{~K}$ & $32.2 \mathrm{~K}$ \\
\hline \multicolumn{2}{|c|}{ Jumlah Video } & 24 & 23 & 27 & 26 \\
\hline \multirow{2}{*}{ viewers } & Total & 1.713 .169 & 765.467 & 565.781 & 49.436 \\
\hline & Rerata & 71.382 & 33.281 & 20.955 & 1.901 \\
\hline \multirow{2}{*}{ Like } & Total & 22.595 & 25.049 & 5.774 & 772 \\
\hline & Rerata & 941 & 1.089 & 214 & 30 \\
\hline \multirow{2}{*}{ Dislike } & Total & 811 & 286 & 162 & 22 \\
\hline & Rerata & 34 & 12 & 6 & 1 \\
\hline \multirow{2}{*}{ Durasi } & Total & $12: 54: 00$ & $5: 34: 00$ & $1: 57: 00$ & $10: 31: 00$ \\
\hline & Rerata & $16: 32$ & $9: 38$ & $21: 24$ & 18:51 \\
\hline \multirow{2}{*}{$\begin{array}{l}\text { Comment } \\
S\end{array}$} & Total & 1512 & 3378 & 578 & 21 \\
\hline & Rerata & 63 & 147 & 21 & 1 \\
\hline
\end{tabular}

○ Sumber: hasil penelitian, data diambil sampai dengan tanggal 07-01-2020

- Akuntansi Pendidik https://www.youtube.com/channel/UCnj2EqN1ch0C0ILvGBMBpCg

○ Accounting Stuff https://www.youtube.com/channel/UCYJLdSmyKoXCbnd-pklMn5Q

○ Ruang Akuntansi https://www.youtube.com/channel/UC3Rlf8WeN1Svmpo0qlUPj5g

- Universitas Terbuka TV https://www.youtube.com/channel/UCoUPOCg0m4hGeHW VPq6QA

Data lengkap video pembelajaran akuntansi di YouTube berdasarkan viewers, like, dislike, durasi, dan comments tersaji dalam lampiran penelitian ini. Sedangkan ringkasannya pemilik akun dan judul video pembelajarannya berdasarkan viewers, like, dislike, durasi, dan comments terbanyak dan terkecil adalah sebagaimana Tabel 2.

Tabel 2 Akun YouTube Materi Akuntansi Dengan Subscribers, Video, Viewers, Like, Dislike, Durasi, dan Comments

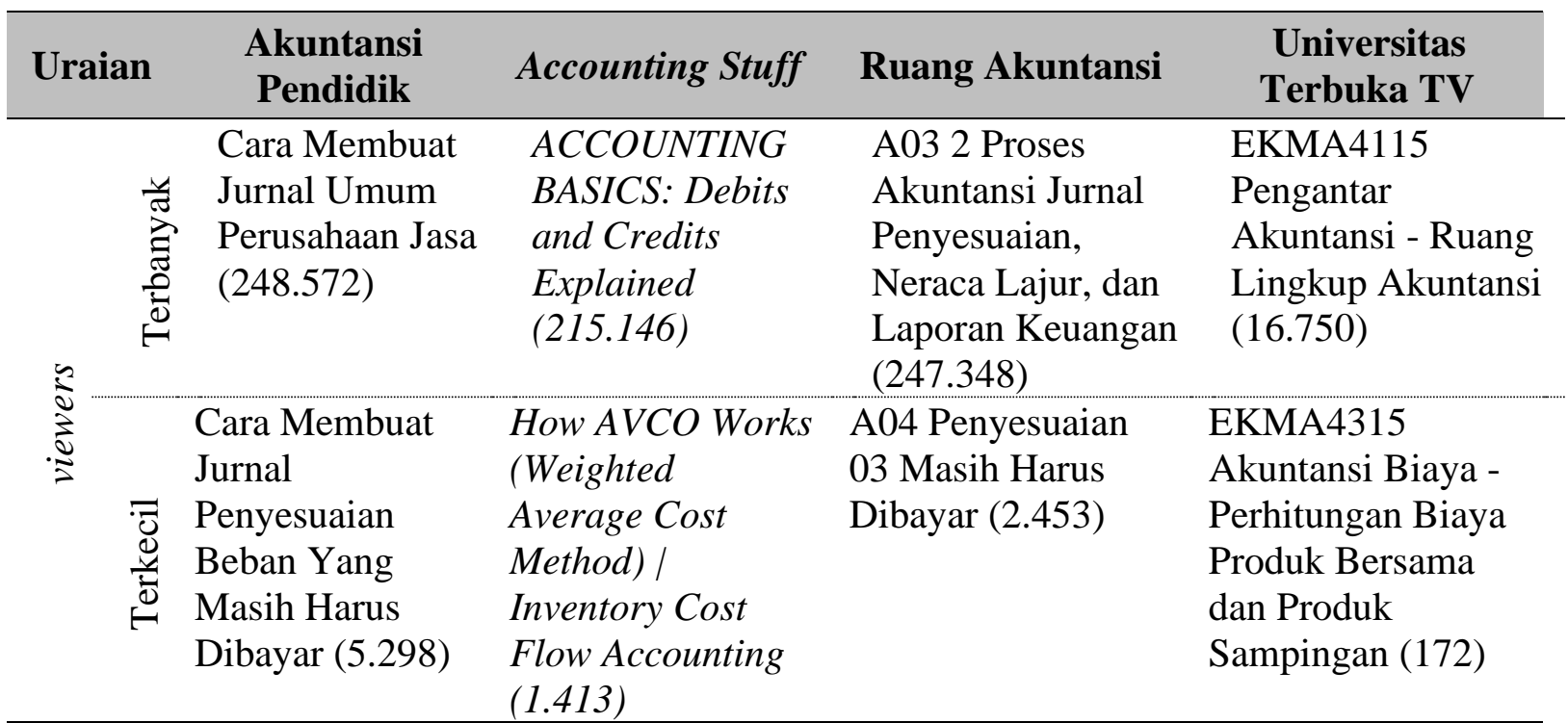




\begin{tabular}{|c|c|c|c|c|c|}
\hline Ura & & $\begin{array}{l}\text { Akuntansi } \\
\text { Pendidik }\end{array}$ & Accounting Stuff & Ruang Akuntansi & $\begin{array}{c}\text { Universitas } \\
\text { Terbuka TV }\end{array}$ \\
\hline \multirow[b]{2}{*}{$\frac{\pi}{3}$} & 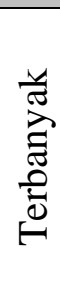 & $\begin{array}{l}\text { Cara } \\
\text { Menentukan } \\
\text { Debit dan Kredit } \\
\text { dengan Tepat } \\
(3.939)\end{array}$ & $\begin{array}{l}\text { Indirect Method } \\
\text { (with Example)| } \\
\text { Cash Flow } \\
\text { Statement (2.055) }\end{array}$ & $\begin{array}{l}\text { A03 } 2 \text { Proses } \\
\text { Akuntansi Jurnal } \\
\text { Penyesuaian, } \\
\text { Neraca Lajur, dan } \\
\text { Laporan Keuangan } \\
\text { (1.992) }\end{array}$ & $\begin{array}{l}\text { EKMA4115 } \\
\text { Pengantar } \\
\text { Akuntansi - Ruang } \\
\text { Lingkup Akuntansi } \\
\text { (213) }\end{array}$ \\
\hline & 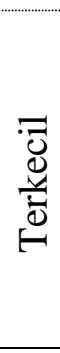 & $\begin{array}{l}\text { Cara Membuat } \\
\text { Jurnal Khusus } \\
\text { Pembelian } \\
\text { Perusahaan } \\
\text { Dagang (45) }\end{array}$ & $\begin{array}{l}\text { How AVCO Works } \\
\text { (Weighted } \\
\text { Average Cost } \\
\text { Method) | } \\
\text { Inventory Cost } \\
\text { Flow Accounting } \\
\text { (81) }\end{array}$ & $\begin{array}{l}\text { A04 Penyesuaian } \\
\text { 03 Masih Harus } \\
\text { Diterima (23) }\end{array}$ & $\begin{array}{l}\text { EKMA4314 } \\
\text { Konsep Biaya } \\
\text { Relevan dalam } \\
\text { Pengambilan } \\
\text { Keputusan Eps } 5 \\
\text { (1) }\end{array}$ \\
\hline \multirow[b]{2}{*}{ 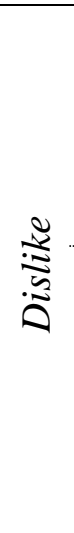 } & 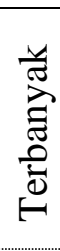 & $\begin{array}{l}\text { Cara Membuat } \\
\text { Jurnal Umum } \\
\text { Perusahaan Jasa } \\
\text { (134) }\end{array}$ & $\begin{array}{l}\text { The INCOME } \\
\text { STATEMENT } \\
\text { Explained (aka. } \\
\text { Profit and Loss / } \\
\text { P\&L) (30) }\end{array}$ & $\begin{array}{l}\text { A03 } 1 \text { Proses } \\
\text { Akuntansi Jurnal } \\
\text { Buku Besar dan } \\
\text { Neraca Saldo (29) }\end{array}$ & $\begin{array}{l}\text { EKMA4115 } \\
\text { Pengantar } \\
\text { Akuntansi - Ruang } \\
\text { Lingkup Akuntansi } \\
\text { (7) }\end{array}$ \\
\hline & 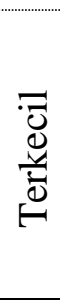 & $\begin{array}{l}\text { Cara Membuat } \\
\text { Jurnal } \\
\text { Penyesuaian } \\
\text { Beban Yang } \\
\text { Masih Harus } \\
\text { Dibayar (2) }\end{array}$ & $\begin{array}{l}\text { Perpetual vs } \\
\text { Periodic Inventory } \\
\text { Systems (1) }\end{array}$ & $\begin{array}{l}\text { terdapat } 10 \text { video } \\
\text { tanpa tanda dislike }\end{array}$ & $\begin{array}{l}\text { Terdapat } 17 \text { video } \\
\text { tanpa tanda dislike }\end{array}$ \\
\hline \multirow{2}{*}{ 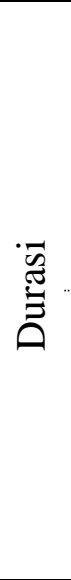 } & 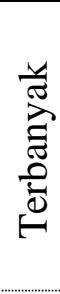 & $\begin{array}{l}\text { Cara Membuat } \\
\text { Kertas Kerja } \\
\text { atau Neraca } \\
\text { Lajur } \\
\text { Perusahaan Jasa } \\
(21: 46)\end{array}$ & $\begin{array}{l}\text { Direct Method } \\
\text { with T Accounts } \\
\text { Cash Flow } \\
\text { Statement (18:12) }\end{array}$ & $\begin{array}{l}\text { A05 Jurnal } \\
\text { Pembalik }(23: 36)\end{array}$ & $\begin{array}{l}\text { EKMA4315 } \\
\text { Akuntansi Biaya - } \\
\text { Pengantar } \\
\text { Akuntansi Biaya } \\
(23: 42)\end{array}$ \\
\hline & 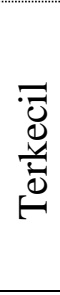 & $\begin{array}{l}\text { Cara Membuat } \\
\text { Laporan } \\
\text { Keuangan dari } \\
\text { Tabel Persamaan } \\
\text { Akuntansi (1:33) }\end{array}$ & $\begin{array}{l}\text { Wait... Debits and } \\
\text { Credits are } \\
\text { BACKWARDS?! } \\
(2: 48)\end{array}$ & $\begin{array}{l}\text { A03 } 3 \text { Proses } \\
\text { Akuntansi Jurnal } \\
\text { Penutup (01:00) }\end{array}$ & $\begin{array}{l}\text { EKMA4314 } \\
\text { Konsep Biaya } \\
\text { Relevan dalam } \\
\text { Pengambilan } \\
\text { Keputusan Eps } 5 \\
(02: 46)\end{array}$ \\
\hline \multirow[t]{2}{*}{ 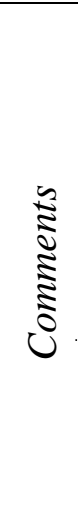 } & 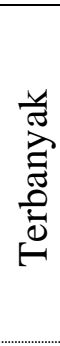 & $\begin{array}{l}\text { Cara } \\
\text { Menentukan } \\
\text { Debit dan Kredit } \\
\text { dengan Tepat } \\
(231)\end{array}$ & $\begin{array}{l}\text { ACCOUNTING } \\
\text { BASICS: Debits } \\
\text { and Credits } \\
\text { Explained (482) }\end{array}$ & $\begin{array}{l}\text { A03 } 2 \text { Proses } \\
\text { Akuntansi Jurnal } \\
\text { Penyesuaian, } \\
\text { Neraca Lajur, dan } \\
\text { Laporan Keuangan } \\
\text { (139) }\end{array}$ & $\begin{array}{l}\text { EKMA4115 } \\
\text { Pengantar } \\
\text { Akuntansi - } \\
\text { Akuntansi Untuk } \\
\text { Perusahaan } \\
\text { Persekutuan dan } \\
\text { Perseroan (4) }\end{array}$ \\
\hline & 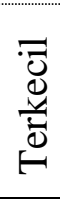 & $\begin{array}{l}\text { Cara Membuat } \\
\text { Jurnal } \\
\text { Penyesuaian } \\
\text { Beban Yang }\end{array}$ & $\begin{array}{l}\text { Wait... Debits and } \\
\text { Credits are } \\
\text { BACKWARDS?! } \\
\text { (51) }\end{array}$ & $\begin{array}{l}\text { Terdapat } 3 \text { video } \\
\text { tanpa comment }\end{array}$ & $\begin{array}{l}\text { Terdapat } 16 \text { video } \\
\text { tanpa comment }\end{array}$ \\
\hline
\end{tabular}




\begin{tabular}{ccccc}
\hline Uraian & $\begin{array}{c}\text { Akuntansi } \\
\text { Pendidik }\end{array}$ & Accounting Stuff & Ruang Akuntansi & $\begin{array}{c}\text { Universitas } \\
\text { Terbuka TV }\end{array}$ \\
\hline Masih Harus & & \\
Dibayar (2) & & \\
\hline
\end{tabular}

Sumber: hasil penelitian, data diambil sampai dengan tanggal 07-01-2020

Selain berdasarkan viewers, like, dislike, durasi, dan comments penelitian ini juga mengidentifikasi materi dan tampilan video pembelajaran akuntansi di Youtube sebagaimana Tabel 3.

Tabel 3 Materi dan Tampilan Video Pembelajaran Akuntansi Di YouTube

\begin{tabular}{|c|c|}
\hline Tampilan Video & Keterangan \\
\hline the & $\begin{array}{l}\text { Akuntansi Pendidik } \\
\checkmark \text { Tampilan sederhana berupa tulisan di kertas HVS hamper } \\
\text { tanpa editan } \\
\checkmark \text { Materi berupa contoh soal dan pembahasannya } \\
\checkmark \text { Pembukaan singkat dan jelas durasi } 20 \text { detik sudah dapat } \\
\text { memberikan gambaran apa yang akan dibahas } \\
\checkmark \text { Wajah pemateri tidak tampak di video } \\
\checkmark \text { Rata-rata viewers tertinggi } 71.382 \\
\checkmark \text { Materi lebih utama daripada tampilan } \\
\checkmark \text { Sudah ada iklan }\end{array}$ \\
\hline 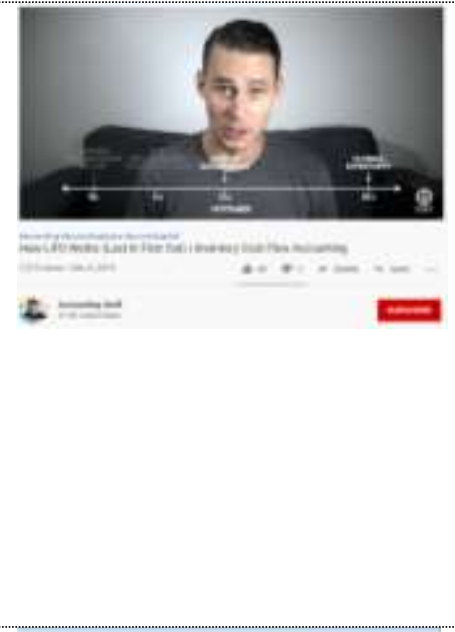 & $\begin{array}{l}\text { Accounting Stuff } \\
\checkmark \text { Tampilan sangat bagus gabungan video, teks dan grafis } \\
\text { dengan proses editing yang kompleks } \\
\checkmark \text { Materi berupa contoh soal dan pembahasannya } \\
\checkmark \text { Pembukaan menarik berupa informasi inti materi yang } \\
\text { ingin disampaikan dan indentitas akun durasi } 10 \text { detik } \\
\checkmark \text { Pemateri sangat nyaman di depan kamera sehingga } \\
\text { ekspresinya menarik } \\
\checkmark \text { Terdapat hastag: \#accounting, \#accountingbasics, } \\
\text { \#accountingstuff } \\
\checkmark \text { Rata-rata viewers 33.281 } \\
\checkmark \text { Materi dan tampilannya sempurna } \\
\checkmark \text { Sudah ada iklan }\end{array}$ \\
\hline $\bar{E} \vdots$ & $\begin{array}{l}\text { Ruang Akuntansi } \\
\checkmark \text { Tampilan bagus gabungan video, teks dan grafis seperti } \\
\text { tampilan slide PowerPoint melalui proses editing sederhana } \\
\checkmark \text { Pembukaan singkat berisi perkenalan dan pokok bahasan } \\
\text { durasi } 5 \text { detik }\end{array}$ \\
\hline $\mathrm{a}=$ & $\begin{array}{l}\checkmark \text { Pemateri tidak tampak dalam tampilan video } \\
\checkmark \text { Rata-rata viewers } 20.955 \\
\checkmark \text { Materi dan tampilan cukup bagus }\end{array}$ \\
\hline
\end{tabular}




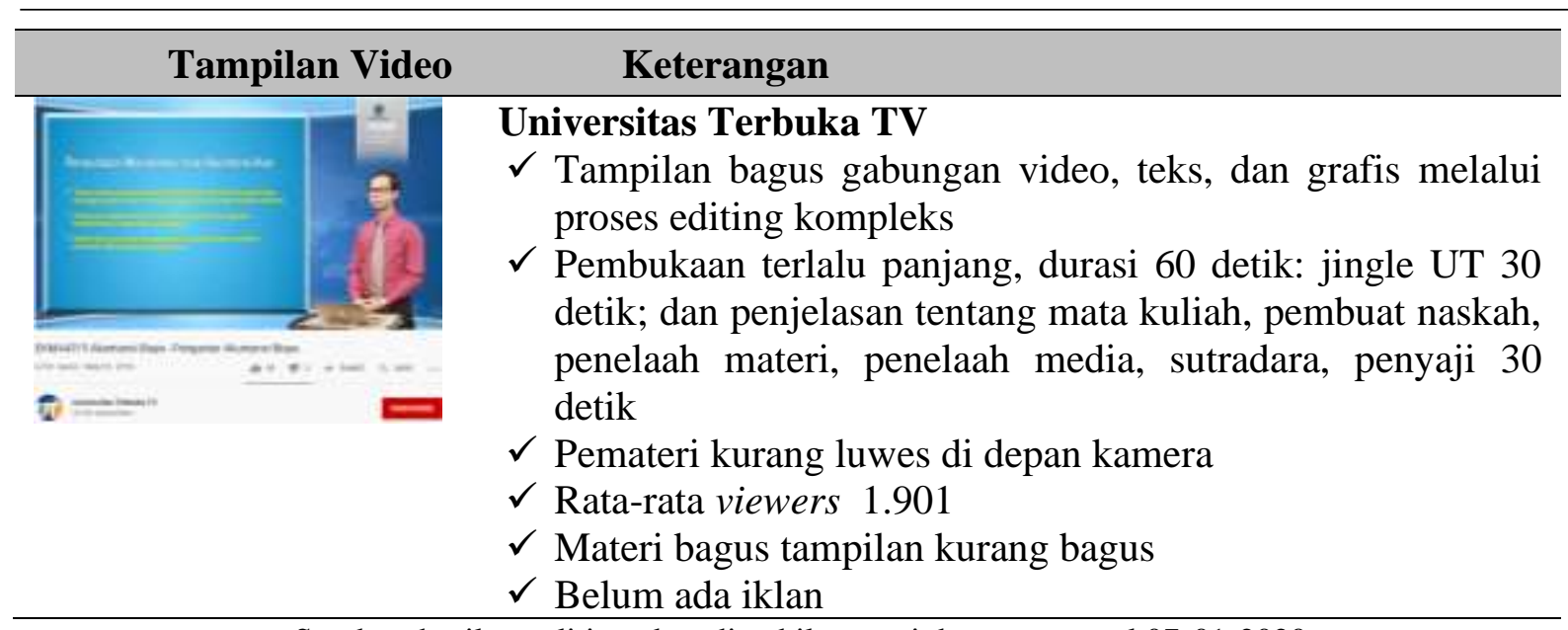

Sumber: hasil penelitian, data diambil sampai dengan tanggal 07-01-2020

Berdasarkan data yang dikumpulkan diketahui bahwa viewers terbanyak video pembelajaran akuntansi di YouTube adalah Akuntansi Pendidikan dengan durasi rata-rata 16:32 menit, namun juga mendapatkan tanda dislike terbanyak. Akun Accounting Stuff viewers cukup banyak dengan rata-rata durasi 9:38 menit dan mendapat tanda dislike lebih sedikit. Berdasar data tersebut sebaiknya dengan durasi 10:00 menit. Semua video baik dengan viewers banyak atau sedikit selalu ada yang memberi tanda like maupun dislike, jadi tanda ini sebaiknya diabaikan. Tampilan pada akun Akuntasi Pendidikan sangat sederhana namun viewers banyak karena materinya mudah dipahami, pada Accounting Stuff materi dan tampilannya sangat bagus namun viewers masih di bawah Akuntansi Pendidikan, artinya materi lebih utama daripada tampilan. Video pada akun Universitas Terbuka TV materinya dibuat sangat bagus oleh tim besar berdasarkan mata kuliah dengan sistem indeks, mempunyai kelemahan karena penyajinya kurang luwes di depan kamera, pembukaan terlalu Panjang, dan materinya lebih banyak konsep dibanding pembahasan contoh soal. Berdasarkan data tersebut lebih baik video pembelajaran dibuat dengan pembukaan singkat yang berisi materi yang dibahas dan lebih banyak membahas contoh soal.

Inovasi pembelajaran akuntansi untuk generasi emas Indonesia yang milenial yang lekat dengan tehnologi informasi, media sosial, dan dawai digital dalam rangka menyongsong Indonesia Emas 2045 dapat memanfaatkan YouTube. Berdasarkan data yang diteliti diketahui sudah ada video pembelajaran akuntansi namun sifatnya tersebar, yang dikelola dengan baik adalah milik Universitas Terbuka namun mempunyai kelemahan pada tampilannya yang kurang luwes dan kurang milenial. Kondisi yang tersebar dan sporatis tersebut tidak memudahkan pemanfaatannya dalam proses pembelajaran.

Altenatif inovasi yang dapat dilakukan adalah membuat akun YouTube terintegrasi antara IAI, Kantor Akuntan Publik, Kantor Konsultan Pajak, dan Perguruan Tinggi yang dapat memenuhi sasaran pendidikan tahun 2020 yang fokus pada sasaran pendidikan tahun 2020 yang fokus pada peningkatan kapasitas, modernisasi proses pembelajaran dengan pemanfaatan tehnologi, penguatan layanan, kemudahan akses, dan dapat dirasakan seluruh lapisan masyarakat sebagaimana 


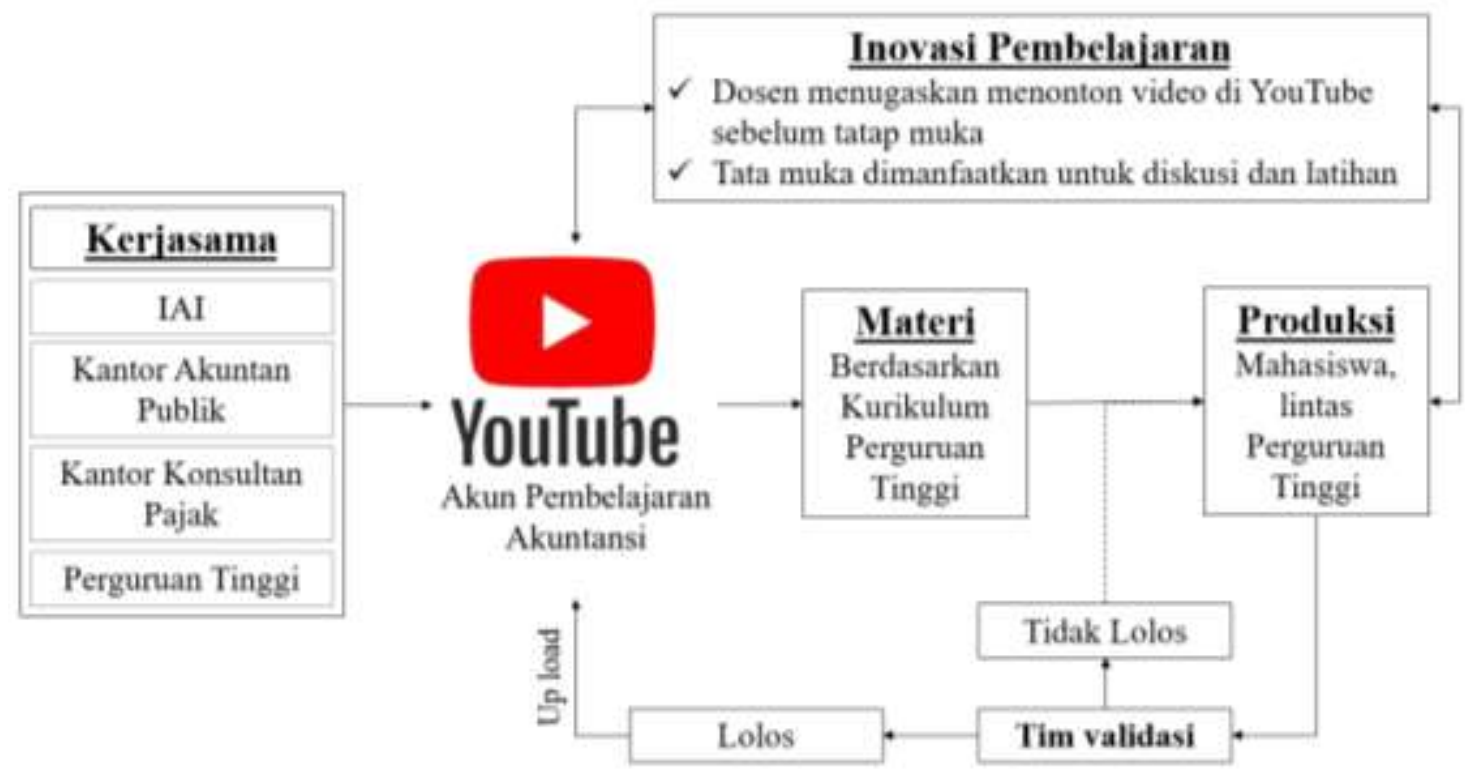

Gambar 1 Inovasi Pembelajaran Akuntansi Terintegrasi

Sumber: Hasil Penelitian

IAI, Kantor Akuntan Publik, Kantor Konsultan Pajak, dan Perguruan Tinggi bersamasama membuat administrasi yang mengelola akun Pembelajaran Akuntansi di YouTube agar tercipta link and match antara mata kuliah dengan kebutuhan dunia kerja. Inovasi ini akan mendukung sasaran pendidikan Indonesia tahun 2020, yaitu: 1) peningkatan kapasitas materi ajar karena akan tersedia banyak video pembelajaran di YouTube, dan peningkatan media pembelajaran secara online; 2) modernisasi proses pembelajaran dengan pemanfaatan tehnologi karena memanfaatkan perkembangan tehnologi informasi, internet, computer, handphone, dan media sosial; 3) penguatan layanan karena mahasiswa dapat belajar online tanpa terikat jam kerja palayanan dan jadwal kuliah tatap muka; 4) kemudahan akses karena dapat dilakukan secara online; dan 5) dapat dirasakan seluruh lapisan masyarakat sebagaimana karena disediakan di YouTube yang bersifat terbuka.

Materi dibuat berdasarkan kurikulum Perguruan Tinggi yang disepakati atau satu buku pegangan kuliah agar dapat diaplikasikan langsung dalam pembelajaran. Berdasarkan materi pembelajaran akuntasi yang sudah disepakati tersebut kemudian di breakdown agar materi pembelajaran tersebut dapat dibuat video dengan durasi sepuluh menit dan diberi judul dengan system indeks dengan memodifikasi yang dilakukan Universitas Terbuka. Seperti dalam akun Accounting Stuff video pembelajaran akuntasi di YouTube diberi hastag (\#) atau tagar dengan tujuan: 1) memudahkan pengguna melakukan pencarian dengan kata kunci sesuai hastag; 2) dapat menghubungkan pengguna pada topik terbaru; dan 3) berlaku secara universal (EliteMarketer, 2020).

Satu materi pembelajaran akuntansi materinya akan sangat banyak, jadi sebaiknya dibuat inovasi agar dapat diproduksi secara masal, bersamaan, dan tampilannya sesuai dengan sasaran pembelajar yang milenial yaitu dengan video tersebut dibuat oleh mahasiswa lintas kampus. Karena inovasi ini melibatkan banyak pihak dan banyak kampus maka harus ada tim kerja yang mengkoordinir pembagian kerja membuat video pembelajaran akuntansi ini, 
misalnya disepakati mahasiswa kampus A membuat video bab satu menjadi sepuluh video, mahasiswa kampus B membuat video bab dua menjadi lima belas video, dan seterusnya. Agar pembuatan video oleh mahasiswa terpantau dan terlaksana maka di masing-masing kampus pembuatannya di bawah koordinasi dosen pengampu mata kuliah yang bersangkutan. Untuk memotivasi mahasiswa pembuatan video dapat dijadikan tugas kuliah sebagai komponen penghitungan nilai akhir mata kuliah yang diikuti.

Video dibuat berdasarkan indeks yang sudah ditetapkan, durasi sekitar sepuluh menit, dengan pembukaan sepuluh detik yang berisi perkenalan dan pokok bahasan. Jika mahasiswa tidak terbiasa tampil di depan kamera, sehingga tidak percaya diri maka video dibuat tanpa menampilkan wajah pemateri, cukup fokus ke materi seperti video akun Akuntansi Pendidik berupa kertas putih yang berisi pembahasan materi dengan tulisan tangan atau seperti video akun Ruang Akuntansi yang mirip dengan akun Akuntansi Pendidikan namun tampilannya seperti slide powerpoint, karena konten lebih penting daripada tampilan. Meski demikia validitas materi harus dijamin, untuk itu sebelum video di upload harus melewati tim validasi, jika masih ada yang harus direvisi dikembalikan ke pembuat, jika sudah sesuai upload di YouTube.

Inovasi pembelajaran ini dapat juga dilaksanakan dengan altenatif lain yaitu diadakan lomba membuat video pembelajaran akuntansi. Mekanismenya sama dengan menentukan materi pembelajaran akuntasi yang akan dijadikan video, di breakdown berdasarkan indeks. Peserta yang mengikuti lomba harus memilih materi yang akan dibuat videonya, agar semua materi tersedia videonya maka satu judul/indeks hanya boleh dibuat dua peserta, jika sudah ada yang memilih harus memilih materi lain. Untuk memotivasi semua peserta yang videonya lolos dari tim validasi akan mendapat sertifikat penghargaan telah mengikuti lomba. Sepuluh video terbaik akan mendapat hadiah dari penyelenggara. Agar video tersebut banyak viewers dan akun Pembelajaran Akuntasi banyak subscribers dapat dibuat ketentuan bahwa salah satu kriteria pemenang adalah jumlah viewers. Pembelajar milenial lekat dengan gawai dan media sosial maka meraka akan berjuang mempromosikan videonya melalui jejaring media sosial yang otomatis akun Pembelajaran Akuntansi juga akan terpublikasi dengan efektif tepat sasaran karena dilakukan oleh mereka yang milenial kepada sesama milenial. Dapat juga dilakukan dengan mengabungkan keduanya, sebagian materi dijadikan tugas kuliah, sebagian yang lain dilombakan.

Inovasi pembelajaran akuntansi di YouTube bagi generasi milenial menyongsong Indonesia Emas ini harus berkelanjutan, tidak boleh berhenti dalam satu tahun untuk itu perlu dibentuk admin yang mengelolanya. Belajar dari pelaksanaan pembuatan satu materi pembelajaran, berikutnya dibuat untuk mata kuliah yang lain dengan demikian tahun-tahun berikutnya akan semakin banyak materi kuliah yang dibuat video, semakin bagus kualitas tampilannya, dan up date. Inovasi pembelajaran ini bersifat sosial bukan komersial, namun memerlukan dana operasional. Video di YouTube dengan viewers banyak dapat mendatangkan penghasilan. Content creator YouTube akan mendapat penghasilan melalui: 1) Youtube ads atau AdSense atau iklan, pihak YouTube membagikan komisi dari perusahaan yang memasang iklan di content berdasarkan viewers yang mengakses iklan di content; 2) Affiliate marketing, pemilik akun YouTube bekerjasama dengan pengusaha yang ingin diiklankan biasanya disertai kode promo atau meletakkan link dalam deskripsi, makin banyak viewers menggunakan kode promo atau klik link makin besar penghasilannya; 3) Jualan, biasanya digunakan perusahaan besar dalam mempromosikan pruduk yang dijualnya; dan 4) Endorsement, berupa iklan yang diselipkan dalam video. Untuk menghitung YouTube ads ada dua indikator yaitu cost per mile sekitar Rp7.000,- per seribu tayangan iklan dan cost per click sekitar Rp5.000,- setiap satu orang mengklik iklan di video. Syaratnya minimal subscriber bertambah 1.000 dalam setahun terakhir dan videonya telah ditonton selama 4.000 jam oleh 
semua viewers setahun terakhir (Utama, 2019 ). Sumber dana yang paling memungkinkan dalam inovasi pembelajaran akuntansi ini adalah endorsement dari Kantor Akuntan Publik, Konsultan Pajak, atau pihak swasta lainnya.

Jika video sudah tersedia di YouTube tahap berikutnya adalah diimplementasikan dalam proses pembelajaran. Dosen memegang peranan penting implementasi pemanfaatan video di YouTube tersebut. Sebagai daya darik agar dosen memanfaatkan video di YouTube dengan maksimal, dapat dilakukan dengan cara memberikan penghargaan bagi dosen yang paling aktif memanfaatkan video tersebut dalam proses pembelajaran. Data keaktifan dosen yang memanfaatkan video di YouTube diperolah dari kolom comment, dosen menugaskan mahasiswa untuk mengisi comment bahwa ia belajar menggunakan video dengan menyebut nama dosen, mata kuliah dan nama kampusnya. Setiap akhir semester berdasarkan comment tersebut dihitung tingkat pemanfaatan video pembelajaran akuntasi oleh dosen. Kendala yang mungkin dihadapi dalam pelaksanaan pembelajaran mmelalui YouTube adalah akan ada mahasiswa yang terbatas kemampuan akses YouTube. Altenatif solusinya dengan menyiapkan free WiFi di lingkungan kampus atau menyiapkan komputer khusus di lingkungan kampus agar mahasiswa dapat mengakses dengan mudah dan murah. Dosen dapat mengambil langkah yang lebih maju dengan menggunakan google classroom atau aplikasi lainnya sebagai aplikasi manajemen pembalajaran berbasis online.

Proses pembelajaran agar efektif tidak hanya tatap muka, namun menerapkan blended learning system secara online dan tatap muka. Mahasiswa diwajibkan sudah harus belajar melalui video di YouTube secara online sebagai bentuk e-learning sebelum kuliah tatap muka. Untuk itu dosen harus menugaskan mahasiswa untuk melihat video pokok bahasan pertemuan berikutnya sebelum pembelajaran tatap muka. Dapat juga dibuat list materi perkulianan berdasarkan pertemuan dengan menambahkan daftar video yang tersedia di YuoTube. Dosen dapat mewajibkan mahasiswa mengisi comment dengan menulis nama dan nomor absen sebagai altenatif absensi telah belajar secara e-learning. Mahasiswa juga boleh mengajukan pertanyaan dalam comment dan pertanyaan tersebut akan dijelaskan dosen pada saat tatap muka. Dengan metode demikian mahasiswa berangkat kuliah dan masuk ruang kuliah dengan semangat, sudah mempunyai tujuan tertentu, sudah mempelajari materi secara madiri, beberapa diantaranya sudah siap dengan pertanyaan karena tidak jelas ketika belajar di YouTube sehingga perkuliahan akan aktif dan menyenangkan. Selain itu tatap muka dapat dimanfaatkan untuk lebih banyak membahas kasus atau soal latihan sehingga perkuliahan dapat memberi lebih banyak ilmu terapan karena ilmu tentang konsep sudah belajar secara online. Untuk memotivasi mahasiswa hadir di kelas tatap muka, karena materi pembelajaran sudah tersedia di YouTube maka sebaiknya setiap tatap muka jika tidak membahas soal latihan disipakan kuis online seperti kahoot atau quizizz. Materi kuis online ini agar tidak memberatkan dosen, sebaiknya dibuat bersama-sama dan dibagi-bagi oleh dosen lintas kampus, satu dosen cukup membuat kuis satu bab atau hanya bagian bab, kemudian dikumpulkan dan share. Inovasi pembelaran akuntansi di YouTube ini juga dapat menciptakan keadilan dan pemerataan mengakses pendidikan dengan mudah. Mahasiswa atau siapapun yang ingin belajar akuntansi dapat belajar secara online dengan kualitas materi pembelajaran yang sama. Inovasi pembelajaran ini akan menjadi altenatif dalam mewujudkan kesetaraan, yang pada akhirnya akan menghadirkan keadilan, dalam belajar. Mahasiswa dapat mengakses materi pembelajaran dengan mudah dan murah, tidak lagi tesekat dengan kampus favorit atau biasa, dosen yang guru besar atau dosen biasa, tetapi tergantung pada pilihan bebas mahasiswa sebagai generasi emas milenial yang akan mewujudkan Indonesia Emas 2045 dengan cara merdeka dalam belajar.

\section{KESIMPULAN DAN SARAN}




\subsection{Kesimpulan}

Indonesia saat ini memasuki era bonus demografi dimana rasio ketergantungannya rendah, artinya penduduk usia produktif lebih dominan disbanding penduduk non-produktif. Generasi muda saat ini yang akan mewujudkan Indonesia Emas 2045. Kemendikbud menetapkan sasaran pendidikan tahun 2020 adalah peningkatan kapasitas, modernisasi proses pembelajaran dengan pemanfaatan tehnologi, penguatan layanan, kemudahan akses, dan dapat dirasakan seluruh lapisan masyarakat. Untuk mewujudkan sasaran tersebut diperlukan inovasi pembelajaran, salah satunya dengan membuat video pembelajaran akuntansi di YouTube. Sudah banyak video pembelajaran akuntansi di YouTube, namun terpisah-pisah dan belum dapat digunakan sebagai media pembalajaran secara tuntas untuk suatu mata pelajaran sehingga perlu kerjasama untuk menyediakan akun YouTube yang berisi materi pembelajaran akuntansi yang komplit sesuai dengan materi ajar mata kuliah agar dapat diimplementasikan dalam proses pembelajaran. Agar video sesuai dengan kamum milenial sebagai pembelajar maka mahasiswa lintas kampus dilibatkan dalam pembuatannya. Inovasi pembelajaran ini akan membantu terwujudnya sasaran Pendidikan tahun 2045 yaitu peningkatan kapasitas, modernisasi proses pembelajaran dengan pemanfaatan tehnologi, penguatan layanan, kemudahan akses, dan dapat dirasakan seluruh lapisan masyarakat.

\subsection{Keterbatasan}

Penelitian ini bersifat konseptual sehingga mempunyai keterbatasan pada implementasinya. Diharapkan tulisan ini dapat dikembangkan pada tahap implementasi.

\subsection{Ucapan Terimakasih}

Ucapan terimakasih disampaikan kepada Pimpinan Badan Pendidikan dan Pelatihan Keuangan atas izin dan bantuan pendanaan penyelesaian penelitian ini.

\section{REFERENSI}

Abdilla, L. A. (2017). Enriching Information Technology Course Materials By Using Youtube. The 5th International Conference On Artificial Intelligence, Computer Science \& Information Technology 2017, (pp. 75-82). Pulau Pinang: WorldConferences.net.

Abi, A. R. (2017). Paradigma Membangun Generasi Emas Indonesia Tahun 2045. Jurnal Ilmiah Pendidikan Pancasila dan Kewarganegaraan, Vol. 2, Nomor 2, Desember, 2(2), 85-90.

Arends, R. I. (2013). Belajar Untuk Mengajar (9 ed.). Jakarta: Salemba Empat.

Ayuwuragil, K. (2018, 4 6). CNN Indonesia. Retrieved 1 5, 2020, from CNN Indonesia: https://www.cnnindonesia.com/teknologi/20180406202852-213-288967/youtube-jadiaplikasi-media-paling-populer-di-indonesia

BAPPENAS. (2019). Rancangan Teknokratik Rencana Pembangunan Jangka Menengah Nasional 2020-2024. Jakarta: BAPPENAS.

BPS. (2018). Statistik Gender Tematik: Profil Generasi Milenial Indonesia. Jakarta: Kementerian Pemberdayaan Perempuan dan Perlindungan Anak.

Darman, R. A. (2017). Mempersiapkan Generasi Emas Indonesia Tahun 2045 Melalui Pendidikan Berkualitas. Jurnal Edik Informatika , 3(2), 73-87.

Dongoran, F. R. (2014). Paradigma Membangun Generasi Emas 2045 Dalam Perspektif Filsafat Pendidikan. Jurnal Tabularasa PPS UNIMED, 11(1), 61-76. 
EliteMarketer. (2020, Januari 8). Elite Marketer. Retrieved from Elite Marketer Web Site: https://elitemarketer.id/traffic/hastag-simbol-sederhana-yang-mampu-tingkatkanmerek-produk-anda-di-media-sosial/

Ferreira, C. M., \& Serpa, S. (2018). Society 5.0 and Social Development. Management and Organizational Studies(5), 26-31. doi:10.5430/mos.v5n4p26

Handayani, M. J. (2013). Studi Eksploratori Lovemarks Pada Pengguna Website Video Sharing Youtube Di Surabaya. Calypta: Jurnal Ilmiah Mahasiswa Universitas Surabaya, 2(2), 1-14.

Hasudungan, A. N., \& Kurniawan, Y. (2018). Meningkatkan Kesadaran Generasi Emas Indonesia Dalam Menghadapi Era Revolusi Industri 4.0 Melalui Inovasi Digital Platform www.indonesia2045.org. Seminar Nasional Multidisiplin 2018 (pp. 51-58). Jombang: UNWAHA Jombang.

Iriawan, S. B. (2017). Mewujudkan Indonesia Emas Tahun 2045 Melalui Pendidikan Kecakapan Abad Ke-21. Bumi Siliwanggi, 1-17. Retrieved 1 5, 2020, from pgsd.upi.edu: http://pgsd.upi.edu/sandi-mewujudkan-generasi-emas-2045-melaluipendidikan-kecakapan-abad-ke-21/

Kemendikbud. (2017). Peta Jalan Generasi Emas Indonesia 2045. Jakarta: Sekjen Kemendikbud.

Kurniawati, D. (2013). The Effectiveness Of Using Youtube Video In Teaching English Grammar Viewed From Students' Attitude. English Education: Jurnal Tadris Bahasa Inggris, 5(1), 52-65.

Lau, E. K. (2017 ). Knowledge Sharing on YouTube. 12th International Conference (pp. 6471). Beijing: Springer .

Luhsasi, D. I. (2017). Youtube: Trobosan Media Pembelajaran Ekonomi Bagi Mahasiswa. Jurnal Ekonomi Pendidikan dan Kewirausahaan, 5(2), 219-229.

Mashoedah. (2015, November). Kajian Penggunaan Media Pembelajaran dalam Pelatihan Peningkatan Kompetensi Profesional Guru. Jurnal Electronics, Informatics, and Vocational Education, 1(1), 17-25.

Mertler, A. (2011). Action Research Mengembangkan Sekolah Memberdayakan Guru. Yogyakarta: Pustaka Pelajar.

Moleong, L. J. (2015). Metodologi Penelitian Kualitatif. Bandung: Remaja Rosdakarya.

Mujiman, H. (2007). Manajemen Pelatihan Berbasis Belajar Mandiri. Yogyakarta: Pustaka Pelajar.

Nata, A. (2015). Model Pembelajaran Yang Dibutuhkan Untuk Menuju Indonesia Emas Tahun 2045. Seminar Nasional Profesional Learning untuk Indonesia Emas (pp. 167179 ). Tangerang Selatan: FITK PRESS.

Permana, R., \& Yusmawati. (2019). Komodifikasi Pesan Dan Viralitas Informasi Dengan Metode "Like, Share, Comment, And Subscribe" Pada Youtube. Media Bahasa, Sastra, dan Budaya Wahana, 25(2), 1-6.

Pradikta, R., \& Haryono, D. (2015). Aplikasi Video Pembelajaran dengan Konsep Youtube. SATIN - Sains dan Teknologi Informasi, 1(1), 20-26.

Rahmat, P. S. (2016 ). Peran Pendidikan Dalam Menyiapkan Generasi Emas. Pendidikan Guru Sekolah Dasar S1, 1(1), 387- 398.

Savira, S. I. (2011). Cognitive Theory In Action: A Discourse Analysis To A Youtube Video About Teaching. Jurnal Psikologi: Teori \& Terapan, 2(1), 58-66. 
Sianipar, A. P. (2013). Pemanfaatan Youtube Di Kalangan Mahasiswa (Studi Penggunaan Youtube di Kalangan Mahasiswa Ilmu Komunikasi FISIP USU Medan dengan Pendekatan Uses and Gratification). FLOW, 2(3), 1-10.

Slam, Z. (2015). Pembelajaran Gotong Royong Inovatif Berbasis Soft Skill Dan Hard Skill Untuk Mewujudkan Indonesia Emas. Seminar Nasional Profesional Learning untuk Indonesia Emas (pp. 127-139). Tangerang Selatan: FITK PRESS.

Sugiyono. (2015). Metode Penelitian Pendidikan, Pendekatan Kuantitatif, Kualitatif, dan $R \& D$. Bandung: Alfabeta.

Tri, S. A., Andry, S., Ikasari, D., \& Dinta, R. D. (2018). Pengembangan Youtube Pembelajaran Abad 21 Berbasis Niteni, Nirokake, Nambahi Untuk Materi Turunan. Prosiding Seminar Nasional Pendidikan Matematika Etnomatnesia (pp. 354-359). Yogyakarta: Universitas Sarjanawiyata Tamansiswa.

Triyono. (2016). Menyiapkan Generasi Emas 2045. Seminar Nasional ALFA-V (pp. 1-9). Klaten: Unwidha Klaten.

UN. (2015, October 21). Transforming Our World: The 2030 Agenda For Sustainable Development. $\quad$ Retrieved 1 5, 2020, from UN: https://www.un.org/en/development/desa/population/migration/generalassembly/docs/ globalcompact/A_RES_70_1_E.pdf

Utama, C. (2019 , May 30 ). Moneysmart. Retrieved from Moneysmart Web Site: https://www.moneysmart.id/berapa-gaji-youtuber/

Utami, E. (2017). Generasi Emas 2045: Indonesia Membutuhkan Kelas Inspirasi Dan Pendidik Super Kreatif. Seminar Nasional Pendidikan (pp. 44-48). Yogyakarta: FKIP UAD.

Wanda, P. (2017, Desember 12). student.cnnindonesia. Retrieved Agustus 25, 2018, from https://student.cnnindonesia.com/edukasi/20171219114411-445-263408/pendidikandan-digitalisasi-di-era-milenial/

Wardoyo, S. M. (2015). Pendidikan Karakter: Membangun Jatidiri Bangsa Menuju Generasi Emas 2045 Yang Religius. Tadrîs, 10(1), 90-103.

Yudhistira, A. W. (2019, 3 6). Katadata. Retrieved 1 5, 2020, from infografik: https://katadata.co.id/infografik/2019/03/06/youtube-medsos-no-1-di-indonesia 